(28.3\% and $10.9 \%$, p-value 0.047 and 0.033 , respectively). There was a trend towards a higher rate of favorable clinical outcomes (mRS 0-2) at 90 days in the ADAPT only group (54\%) compared to the ADAPT with Solumbra salvage group (31\%, p-value 0.21).

Conclusion Among patients treated with mechanical thrombectomy using an ADAPT-first approach, those requiring Solumbra salvage had significantly-higher rates of unfavorable clinical outcome and death at 90 days.

\begin{tabular}{|c|c|c|c|c|}
\hline & $\begin{array}{l}\text { All patients } \\
(n=59)\end{array}$ & $\begin{array}{l}\text { ADAPT only } \\
(n=46)\end{array}$ & $\begin{array}{l}\text { ADAPT with solumbra } \\
\text { salvage }(n=13)\end{array}$ & $\begin{array}{l}\mathrm{p}- \\
\text { value }\end{array}$ \\
\hline $\begin{array}{l}\text { Symptomatic } \\
\text { intraparenchymal } \\
\text { hemorrhage }\end{array}$ & $1.7 \%$ & $2.2 \%$ & 0 & 1 \\
\hline $\begin{array}{l}\text { Symptomatic } \\
\text { subarachnoid h }\end{array}$ & $1.7 \%$ & 0 & $7.7 \%$ & 0.22 \\
\hline $\begin{array}{l}\text { Neuro-ICU length of stay, } \\
\text { days }\end{array}$ & 3.1 & 2.6 & 4.6 & 0.11 \\
\hline $\begin{array}{l}\text { Hospital length of stay, } \\
\text { days }\end{array}$ & 6.6 & 6.2 & 8 & 0.22 \\
\hline Discharge to home: & $22 \%$ & $26 \%$ & $8 \%$ & 0.26 \\
\hline $\begin{array}{l}\text { In-Hospital Mortality I } \\
\text { Discharge to Hospice }\end{array}$ & $14 \%$ & $9 \%$ & $31 \%$ & 0.06 \\
\hline 90 day Mortality & $17 \%$ & $11 \%$ & $39 \%$ & 0.033 \\
\hline 90 day mRS 4-6 & $36 \%$ & $28 \%$ & $62 \%$ & 0.047 \\
\hline 90 day mRS $0-2$ & $49 \%$ & $54 \%$ & $31 \%$ & 0.21 \\
\hline
\end{tabular}

Disclosures J. Delgado Almandoz: 2; C; Medtronic Neurovascular, Penumbra, Inc. Y. Kayan: 2; C; Medtronic Neurovascular, Penumbra, Inc. M. Young: None. J. Fease: None. J. Scholz: None. A. Milner: None. P. Roohani: None. T. Hehr: None. M. Mulder: None. R. Tarrel: None.

\section{E-002 PROLONGATION OF POLYMETHYLMETHACRYLATE CEMENT WORKING TIME DURING PERCUTANEOUS KYPHOPLASTY WITH ICE BATH COOLING}

B Kim. Texas Stroke Institute, Plano, TX

\subsection{6/neurintsurg-2016-012589.74}

Aim To study the effect of cooling of polymethylmethacrylate dough in an ice bath to prolong working time of cement during percutaneous kyphoplasty.

Materials and methods Polymethylmethacrylate dough filled cement cartridges were placed in a saline ice bath for varying lengths of time to study the effect of cooling cartridges on working time of cement during percutaneous kyphoplasty using the Kyphon ${ }^{\circledR}$ (Medtronic Spine, Sunnyvale, CA, USA) Balloon Kyphoplasty system.

Results Cement dough was easily injectable through the bone filler with the injection gun immediately after removal from an ice bath at 15, 30, and 60 minutes of storage. Consistency of the mixture was ideally doughy at all time points. After 15 minutes at room temperature, the mixture continued to be injectable with slightly more resistance at these time points. The mixture was more firm yet maintained a doughy consistency. Cement dough could not be injected after 120 minutes

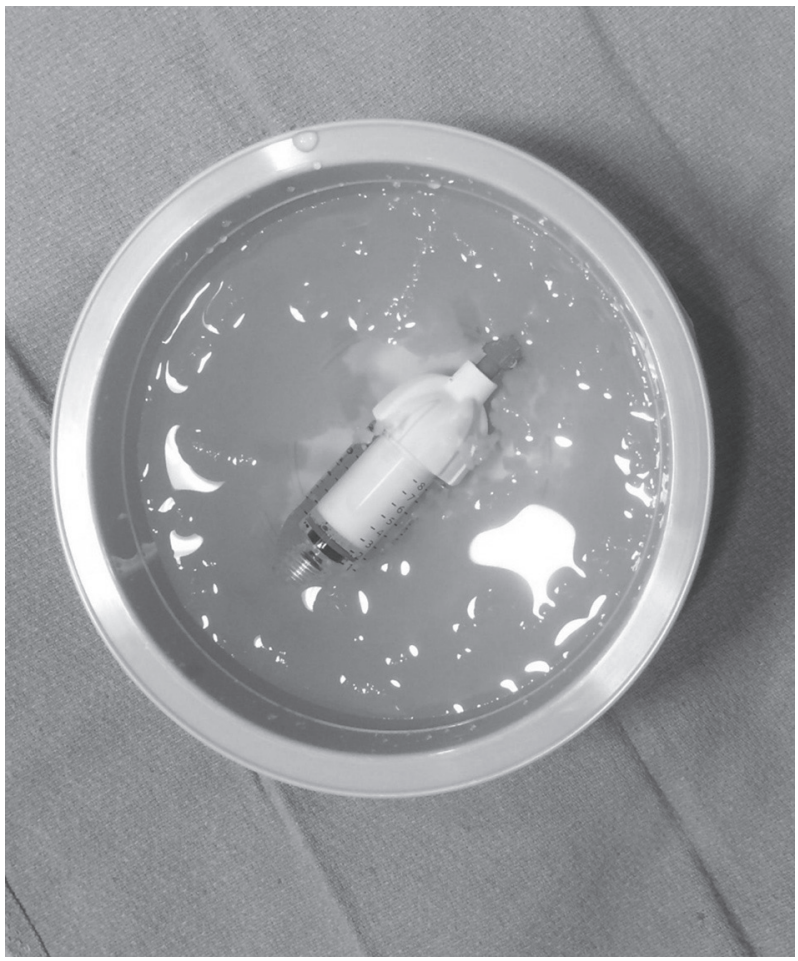

Abstract E-002 Figure 1

of storage, either immediately after removal or after 15 minutes at room temperature.

Conclusion We demonstrate the prolongation of working time of polymethylmethacrylate cement in percutaneous kyphoplasty using ice bath cooling of dough filled cement cartridges. Cement dough was injectable after storage in an ice bath for up to 60 minutes. In the clinical setting, intraprocedual cooling using this simple, low cost technique may extend the working time of polymethylmethacrylate for the operator and may improve the utility of a single Balloon Kyphoplasty kit when treating multiple vertebral compression fractures.

Disclosures B. Kim: None.

\section{E-003 EVALUATION OF STRATEGIES TO REDUCE TIME TO REVASCULARIZATION IN ACUTE ISCHEMIC STROKE}

${ }^{1} \mathrm{~A}$ Doerr, ${ }^{2} \mathrm{~S}$ Jenkins, ${ }^{3} \mathrm{~J}$ Davis. ${ }^{1}$ Northwestern Medicine, Chicago, $\mathrm{Li}_{i}{ }^{2}$ Mennonite College of Nursing, Illinois State University, Normal, IL; ${ }^{3}$ Central DuPage Hospital, Winfield, IL

\subsection{6/neurintsurg-2016-012589.75}

Background Stroke is significant cause of morbidity, disability and mortality in the United States today. There is growing support for the need for process improvement, specifically, reducing time to reperfusion in endovascular stroke therapy (EVT) to improve functional outcomes. It is suggested that every 30 minutes delay in revascularization of acute ischemic stroke leads to a $10.6 \%$ decrease in the potential for a good functional outcome (Khatri et al., 2009).

Purpose To identify the impact on specific hospital based process improvement strategies in the acute ischemic stroke patient population undergoing endovascular therapy with specific intent to decrease median arrival to revascularization time, thus increasing the potential for good functional outcome. We 
seek to evaluate the efficacy of three hospital-based methods to improve time to revascularization in EVT for stroke: early notification, streamlined transport process and utilization of feedback tool.

Methods The project includes a pre and post intervention retrospective review of patient 18 years or older, admitted through the emergency department, with hospital admission between January 1, 2014 and December 31, 2015, who undergo EVT for treatment acute ischemic stroke. Primary outcome variable: time from arrival to revascularization (first pass) and secondary outcome variables: functional outcome analysis utilizing pre procedure, post procedure and discharge modified Rankin score (MRS) 30 and 90 day MRS. The data points will be collected using the Stroke Time PI project tool based on the America Heart Association's Get with the Guidelines-Stroke (GWTG).

Results A total of 17 consecutive ED arrival endovascular ischemic stroke patients were reviewed, pre PI (Group 1, $\mathrm{n}=9$ ) and post PI (Group 2, $\mathrm{n}=8$ ). The timeline breakdown from patient arrival to revascularization is shown in Table 1. Preliminary analysis of the primary outcome demonstrates significant improvement in door to revascularization between the pre and post PI groups, 2:56 and 2:14 $(\mathrm{p}<.05)$ respectively, a statistically significant 40 minute decrease in time to treatment.

Conclusions Despite the relatively small sample size for the study, this evaluation provides evidence based practice strategies which could be implemented at stroke centers to reduce door to revascularization time in EVT. These strategies are also theorized to positively impact stroke outcomes due to the improvement in treatment times and will be reported with the final study analysis.

\begin{tabular}{|c|c|c|c|c|c|}
\hline & $\begin{array}{l}\text { Pre PI } n=8 \\
\text { mean }\end{array}$ & SD & $\begin{array}{l}\text { Post PI } n=9 \\
\text { mean }\end{array}$ & SD & Sig \\
\hline Arrival to angio suite (hh:mm) & 1:59 & $0: 39$ & 1:26 & $0: 28$ & $\mathrm{p}=0.57$ \\
\hline $\begin{array}{l}\text { Angio suite to groin puncture } \\
\text { (hh:mm) }\end{array}$ & 0.27 & $0: 08$ & $0: 25$ & $0: 12$ & $p=0.73$ \\
\hline $\begin{array}{l}\text { Groin puncture to first pass } \\
\text { (hh:mm) }\end{array}$ & $0: 28$ & $0: 15$ & $0: 22$ & $0: 11$ & $p=0.35$ \\
\hline $\begin{array}{l}\text { Time total: arrival to first pass } \\
\text { (hh:mm) }\end{array}$ & 2:56 & $0: 36$ & 2:14 & $0: 36$ & $\mathrm{p}<0.05$ \\
\hline
\end{tabular}

Disclosures A. Doerr: None. S. Jenkins: None. J. Davis: None.

\section{E-004 FACTORS ASSOCIATED WITH SUCCESSFUL REVASCULARIZATION USING THE ASPIRATION COMPONENT OF ADAPT IN THE TREATMENT OF ACUTE ISCHEMIC STROKE}

J Mascitelli, C Kellner, C Oravec R Deleacy, E Oermann, S Paramasivam, J Fifi, J Mocco. Mount Sinai Hospital, New York, NY

10.1136/neurintsurg-2016-012589.76

Introduction The direct aspiration first pass (ADAPT) technique has been shown to be fast, cost-effective, and associated with excellent angiographic and clinical outcomes in the treatment of acute ischemic stroke (AIS). ${ }^{1-4}$ It would be useful to know which pre-procedural factors are associated with successful revascularization using aspiration alone to help choose a method of thrombectomy for patients with AIS.

Methods This is a retrospective review of patients with AIS treated with thrombectomy. Cohort 1 ( $\mathrm{n}=44)$ included ADAPT cases in which aspiration alone was successful (TICI 2 b or 3$)$. Cohort $2(\mathrm{n}=32)$ included ADAPT cases in which aspiration was unsuccessful $(\mathrm{n}=23)$ as well as non-ADAPT cases in which there was a clear intent to use ADAPT but the aspiration catheter could not be navigated to the thrombus $(\mathrm{n}=9)$. The majority of patients in Cohort 2 were ultimately treated with a stent retriever (SR). Cases in which SRs were used primarily with distal aspiration (a.k.a. Solumbra) were excluded. CTH/CTA/DSAs were graded for dense vessel sign, aortic arch type, number of reverse curves and severe stenosis on the path to the target vessel by an interventional radiologist who was blinded to study design.

Results There was no difference between cohorts with regards to gender, race, medications, NIHSS score, use of IV TPA, site or sidedness of thrombus, process times, presence of a dense vessel sign, aortic arch type, presence of severe stenosis, and guide/aspiration catheters used. Patients in Cohort 1 were on average younger (66.5 vs. 74.1 years, $p=0.025)$. There was a trend for more patients in Cohort 2 to have atrial fibrillation (AFib)/arrhythmias $(62.5 \%$ vs. $45.5 \%, \mathrm{p}=0.168)$ and there was a trend for more patients in Cohort 2 with a cardiogenic stroke etiology $(78.1 \%$ vs. $56.8 \%, \mathrm{p}=0.086)$. There was a trend for fewer reverse curves on average in Cohort 1 (1.7 vs. 2.3, p = 0.107).

Conclusions Aspiration success was associated with younger age. There was a trend for aspiration failure to be associated with cardiogenic etiology and more difficult vascular anatomy. Our findings suggest that the ADAPT technique can be used for the vast majority of patients but it may be beneficial to use a SR primarily when performing thrombectomy in the elderly. Further research analyzing thrombus characteristics is needed.

\section{REFERENCES}

1 Turk AS, Frei D, Fiorella D, et al. ADAPT FAST study: a direct aspiration first pass technique for acute stroke thrombectomy. J Neurointerv Surg 2014;6(4):260-4.

2 Turk AS, Turner R, Spiotta $A$, et al. Comparison of endovascular treatment approaches for acute ischemic stroke: cost effectiveness, technical success, and clinical outcomes. J Neurointerv Surg 2015;7(9):666-70.

3 Delgado Almandoz JE, Kayan Y, Young ML, et al. Comparison of clinical outcomes in patients with acute ischemic strokes treated with mechanical thrombectomy using either Solumbra or ADAPT techniques. J Neurointerv Surg 2015.

4 Kowoll A, Weber A, Mpotsaris A, et al. Direct aspiration first pass technique for the treatment of acute ischemic stroke: initial experience at a European stroke centercenter. J Neurointerv Surg 2016;8(3):230-4.

Disclosures J. Mascitelli: None. C. Kellner: None. C. Oravec: None. R. DeLeacy: None. E. Oermann: None. S. Paramasivam: 2; C; Microvention. J. Fifi: 2; C; Microvention. 4; C; Lazarus Effect. J. Mocco: 1; C; National/International PI/CoPI for: THERAPY (PI), FEAT (PI), INVEST (Co-PI), COMPASS (Co-PI), LARGE (Co-PI), COAST (Co-PI), POSITIVE (Co-PI). Steering Committee for MAPS Trial. 2; C; Rebound Therapeutics, TSP Inc, Cerebrotech, Lazarus Effect, Pulsar, Medina. 4; C; Blockade Medical, TSP Inc., Lazarus Effect, Medina. 